\title{
Enzyme- mediated coupling of a bi-functional phenolic compound onto wool to enhance its physical, mechanical and functional properties
}

Kh. M. Gaffar Hossain ${ }^{1}$, María Díaz González ${ }^{1}$, Ascensión Riva Juan ${ }^{2}$ and Tzanko Tzanov ${ }^{1}{ }^{*}$

${ }^{1}$ Group of Molecular and Industrial Biotechnology, Department of Chemical Engineering,

${ }^{2}$ Institute of Textile Research and Industrial Cooperation of Terrassa (INTEXTER)

Technical University of Catalonia,

Terrassa, Barcelona, Spain.

Fax:+34937398225; E-mail: tzanko.tzanov@upc.edu 


\begin{abstract}
Wool fibres have been modified with nordihydroguaiaretic acid (NDGA) to improve their performance at use. This water insoluble bi-functional phenolic compound has been grafted on wool through a laccase enzyme catalyzed reaction in an aqueous-ethanol mixture. The capacity of laccase to oxidise NDGA in this aqueous-organic medium has been studied electrochemicaly. The increase of $\mathrm{CH}_{2}, \mathrm{CH}_{3}$ and aromatic groups signal in the DRIFT spectra, together with SEM images of the enzymatically-modified fabrics confirmed the covalent grafting of NDGA on wool. This one step enzymatic process for grafting of NDGA improved the physical and mechanical properties of wool fabrics such as shrink resistance, crease recovery and tensile strength. Furthermore, the NDGA imparted to the textile material strong antioxidant activity and UV-protection.
\end{abstract}

Keywords: wool, nordihydroguaiaretic acid, laccase, aqueous-organic medium, surface modification, shrink resistance, UV protection 


\section{Introduction}

The outer scales of the wool fibre form a cuticle layer which comprises about $6-16 \%$ of the mass of the fibre. Cuticule scales control important properties of wool, such as friction, handle, diffusion of dyes, and felting propensity [1]. Felting is a serious problem of wool especially during washing. The felting changes not only the garment dimensions but also the appearance of the fibres. The most widely used even today shrink-resist finishing for wool is the chlorine-Hercosett process [2]. However, this effective process, consisting in a strong acid chlorine treatment followed by polymer resin application, has one important disadvantage - the release of adsorbable organic chlorides. Extensive efforts have been made to find environmentally acceptable alternatives to this process to produce soft-handle shrinkresistant wool. Various enzymatic methods have been used to this end including the application of proteases, lipases, protein disulphide isomerase and transglutaminase [3-5]. Proteases can be used in order to reduce felting shrinkage of wool by hydrolysing the cuticle cells of the fibres and thereby reducing the inter-fibre friction. However, the effect of proteases on wool is difficult to control, and is not sufficiently predictable and reproducible for industrial applications. To overcome this limitation two alternative approaches have been proposed. One is to limit the action of the proteases only to the surface of the fibres by increasing their molecular size, e.g. grafting soluble polymers adducts [6], but the enzyme modification is rather complicated and not easily reproducible, requiring expensive crosslinking agents and purification thereafter. The other recently developed approach is to apply transglutaminases (TG) as a pre/post-treatment [7-10], to prevent or compensate the reduction of tensile strength and degradation of wool in protease treatment. Optimisation of the latter process towards simultaneous application of TG and protease was developed recently in our lab in order to reduce time, energy consumption and costs [11]. 
In addition to soft-handle and shrink-resistance, nowadays there is great demand for producing textile goods with multifunctional properties such as antioxidant activity [12], UV protection [13], and wrinkle recovery [14]. Special attention has been paid to the photoyellowing of wool upon exposure to sunlight [15]. Wool's susceptibility to photo-yellowing is attributed to its inherent absorption in the UVB (280-320 nm) and UVA (320-400 nm) regions of the light spectra mainly due to the presence of the aromatic amino acid residues. The photo-yellowing tendency of wool is far more serious than with other commonly used fibres (nylon, acrylics, cotton, etc.) and represents a significant commercial handicap. The effectiveness of different UV absorbers in improving wool photostability has been reported $[16,17]$ and synergistic effect of UV absorbers and antioxidants has been found [18].

The naturally occurring phenolic compound nordihydroguaiaretic acid (NDGA) has been widely used as an antioxidant [19]. This compound has also been reported to act as a protective agent against keratosis caused by exposure to UV light [20]. Furthermore, NDGA due to the presence of two functional ortho-catechols in its structure (Scheme 1) can act as a cross-linking agent improving the mechanical properties of synthetic collagen [21, 22].

Functionalisation of wool with this compound could provide a set of added value properties such as antioxidant activity and UV protection bound to improvement in physical and mechanical properties. The phenolic structure of this compound suggests the possibility for the application of enzymatic tools, e.g. polyphenol oxidases [23, 24] for permanent grafting of wool. However, the water insolubility of NDGA is a major constraint to design the enzymatic process, since native enzymes, and especially oxidases, do not commonly possess a significant catalytic activity in organic media. However, as we reported recently it was possible to carry out laccase catalysed enzymatic grafting of insoluble phenolic compounds on wool working in aqueous-organic mixture [25]. 
The objective of the present work is to design a simple one step enzymatic process for grafting of NDGA on wool using laccases in order to produce multifunctional wool textiles with improved wrinkle, shrink resistance and tensile strength in addition to antioxidant activity and UV stability and protection. 


\section{Experimental Part}

2.1 Materials and methods

Laccase (EC 1.10.3.2 Trametes sp. laccase, Laccase L603P; 0.125 g prot. per g solid; 0.14 U/mg prot.) was provided by Biocatalysts, UK. Enzyme activity (U) was defined as $\mu$ mol of guaiacol oxidized per min at $\mathrm{pH} 4$ and $40^{\circ} \mathrm{C}\left(\varepsilon_{\max } 6400 \mathrm{M}^{-1} \mathrm{~cm}^{-1}\right)$. Nordihydroguaiaretic acid (NDGA), methanol, sodium tartrate, hydrochloric acid, 1-diphenyl-2-picrylhydrazyl radical $\left(\mathrm{DPPH}^{\bullet}\right)$ were purchased from Sigma-Aldrich. Ethanol $96 \%$ was purchased from Panreac. All chemicals used in this work were of the highest grade commercially available.

\subsection{Enzymatic oxidation of NDGA}

The enzymatic oxidation of NDGA by laccase was studied by means of cyclic voltammetry using a $\mu$ Autolab Type III (EcoChemie) potentiostat/galvanostat controlled by Autolab GPES software version 4.9. All experiments were carried out in a $20 \mathrm{~mL}$ Metrohm cell with a threeelectrode configuration. The working electrode was a glassy carbon (GCE) with $3 \mathrm{~mm}$ surface diameter (Metrohm). The counter and reference electrodes were platinum (Metrohm) and $\mathrm{Ag} / \mathrm{AgCl}$ (Metrohm) electrode, respectively. The renewal of the glassy carbon surface was achieved by polishing with 1.0 and $0.3 \mu \mathrm{m}$ alpha-alumina (Micropolish, Buehler) on a microcloth polishing pad (Buehler), followed by washing in an ultrasonic Selecta bath for 2 min. For the experiment with laccase $5 \mu \mathrm{L}$ sample of $3 \mathrm{U} / \mathrm{mL}$ enzyme solution was dropped onto the polished surface of the GCE and allowed to dry for $15 \mathrm{~min}$ at room temperature. Study of the dependence of the substrate concentration on the catalytic current was carried out for estimation of the kinetic parameters. Cyclic voltammograms were recorded in substrate solutions of different concentration ranging between 0.05 and $1 \mathrm{mM}$. Data fitted to the following adaptation of the Michaelis-Menten equation [26]: 


$$
I=\frac{I_{\max }[S]}{[S]+K_{M}^{a p p}}
$$

where $[S]$ is the bulk concentration of the substrate, $I$ and $I_{\max }$, the catalytic current and maximum catalytic current, respectively, and $\mathrm{K}_{M}^{a p p}$, the apparent Michaelis-Menten constant. $\mathrm{I}_{\max }$ and $\mathrm{K}_{M}^{a p p}$ were calculated from Hanes-Woolf linearisation of the above equation.

\subsection{Wool preparation}

Woven $100 \%$ wool fabric supplied by Lokateks (Slovenia) was washed previously to the enzymatic treatment with $1 \mathrm{~g} / \mathrm{L}$ non-ionic surfactant Cotemol NI (Colorcenter, Spain) in liquor to good ratio $20: 1$ in a laboratory winch machine $\left(0.1 \mathrm{M} \mathrm{Na}_{2} \mathrm{CO}_{3}, \mathrm{NaHCO}_{3}\right.$ buffer $\mathrm{pH}$ 9) at $40{ }^{\circ} \mathrm{C}$ for $30 \mathrm{~min}$. Thereafter the fabric was bleached at the same bath ratio with 0.1 $\mathrm{mL} / \mathrm{L}$ of $30 \% \mathrm{H}_{2} \mathrm{O}_{2}\left(0.1 \mathrm{M} \mathrm{Na}_{2} \mathrm{CO}_{3}, \mathrm{NaHCO}_{3}\right.$ buffer $\mathrm{pH}$ 9) at $55^{\circ} \mathrm{C}$ for $1 \mathrm{~h}$.

\subsection{Enzymatic modification of wool}

Samples of wool fabric were incubated in $80 / 20$ (v/v \%) buffer/EtOH solution with $14 \mathrm{U} / \mathrm{mL}$ laccase and $5 \mathrm{mM}$ NDGA. The reaction was allowed to proceed for $2 \mathrm{~h}$, at $40{ }^{\circ} \mathrm{C}$, and $30 \mathrm{rpm}$

in a laboratory dying machine Ahiba (Datacolor). Control samples without laccase and NDGA and treated only either with laccase or NDGA were also prepared at the same treatment conditions as above. After the enzymatic treatment the samples were washed extensively in ethanol (96\%) for $6 \mathrm{~h}$ at room temperature and then with distilled water. After washing the samples were dried at $50^{\circ} \mathrm{C}$ for $2 \mathrm{~h}$. 
2.5. Diffuse reflectance infrared Fourier transform (DRIFT) analysis

DRIFT spectra of the wool fabrics before and after treatment, over the $400-4000 \mathrm{~cm}^{-1}$ range, were collected by a Perkin Elmer Paragon 1000 FT-IR spectrometer, performing 100 scans for each spectrum. All spectra were normalized before characterization at $1230 \mathrm{~cm}^{-1}$ corresponding to the amide I peak.

\subsection{Surface morphology}

The surface morphology of modified and unmodified wool fabrics was studied by scanning electron microscopy (SEM, JSM 5610 scanning electron microscope (JEOL Ltd, Japan)) obtaining microscopic photographs with magnification x1500 of the surface.

\subsection{Fabric shrinkage}

Fabric shrinkage after washing was assessed according to ISO 6330 as described in IWS Test Method 31. The fabrics were washed in a Wascator washing machine (Wascator FOM71 special, Electrolux-wascator, Sweden) in one cycle of washing program 7A for relaxation and three cycles program $5 \mathrm{~A}$ for felting shrinkage, both at $40{ }^{\circ} \mathrm{C}$ with a load (polyester fabric) and standard detergent. All samples were tumble-dried after washing and conditioned at room temperature before measuring the area shrinkage. The results were expressed as percentage of area shrinkage and are mean value of the shrinkage measured on three different samples.

\subsection{Tensile strength}

The samples were conditioned at $23{ }^{\circ} \mathrm{C}, 60 \%$ relative humidity for $24 \mathrm{~h}$ prior to evaluation. Tensile strength was determined using a tensile tester PT-250 (Investigación Sistemas Papeleros, S.L. Spain) in a standard procedure with 2 Kgf maximum capacity load and 115 $\mathrm{mm} \mathrm{min}^{-1}$ speed. The tensile resistance values are given as the mean of 9 samples measured. 


\subsection{Crease recovery angle (CRA)}

Crease recovery angle (CRA) was measured using Shirley Crease Recovery Tester, (Shirley developments Ltd, Manchester, England) according to standard method ISO 2313-1972. The specimen dimension was 40x15 mm and creased under a weight of $500 \mathrm{~g}$ for $5 \mathrm{~min}$ and then allowed to recover for $5 \mathrm{~min}$. The samples were conditioned at $20 \pm 2{ }^{\circ} \mathrm{C}$ and $65 \pm 2 \%$ relative humidity $(\mathrm{RH})$ for $24 \mathrm{~h}$ before testing. The average value and standard deviation of the sample was calculated according to the standard.

\subsection{Antioxidant activity}

Radical scavenging activity of the modified wool was determined measuring the decrease in absorbance of 1,1-diphenyl-2-picrylhydrazyl radical $\left(\mathrm{DPPH}^{\bullet}\right)$ at $515 \mathrm{~nm}$. Samples of modified wool (200 mg) were incubated with $3 \mathrm{~mL}$ of a $3 \times 10^{-5} \mathrm{M} \mathrm{DPPH}^{\bullet}$ solution in $\mathrm{MeOH}$ at room temperature in the dark for $1 \mathrm{~h}$. Solution containing unmodified wool was used as a blank, while samples of wool treated with laccase or NDGA were used as controls. The experiment was carried out in triplicate. The antioxidant activity was calculated using the following formulae:

$$
\text { Inhibition of DPPH (\%) }=\left(1-\frac{A_{\text {Sample }}}{A_{\text {Blank }}}\right) \times 100
$$

\subsection{UV- Protection of modified surface}

Ultraviolet transmittance spectra were obtained using the Ultraviolet Transmittance Analyser UV1000F of Labsphere. Each spectrum was the average result of 10 measurements. 
The Ultraviolet Protection Factor (UPF) of the fabrics was determined by the in vitro method, according to the indications of the standard AS/NZ 4399:1996. The UPF of each specimen is calculated according to the following equation:

$$
U P F_{i}=\frac{\sum_{\lambda=290}^{400} E_{\lambda} \times S_{\lambda} \times \Delta \lambda}{\sum_{\lambda=290}^{400} E_{\lambda} \times S_{\lambda} \times T_{\lambda} \times \Delta \lambda}
$$

where: $E_{\lambda}$ : CIE relative erythemal spectral effectiveness; $S_{\lambda}$ : solar spectral irradiance; $T_{\lambda}$ : spectral transmittance of the fabric; $\Delta \lambda$ : wavelength step in $\mathrm{nm}$ and $\lambda$ is wavelength in $\mathrm{nm}$. The rated UPF of the sample is calculated introducing a statistical correction. Starting from the standard deviation of the mean UPF, the standard error in the mean UPF is calculated for a 99\% confidence level. The Rated UPF will be the mean UPF minus the standard error, rounded down to the nearest multiple of five. For UPF ratings of 55 or greater, the term $50+$ shall be used.

$$
U P F=\overline{U P F}-t_{\alpha / 2, N-1} \cdot \frac{S D}{\sqrt{N}} \ldots
$$

where: $\overline{\mathrm{UPF}}$ : mean UPF, $\mathrm{t}_{\alpha / 2, \mathrm{~N}-1}: \mathrm{t}$ variate for a confidence level $\alpha=0.005$ and SD: Standard deviation of the mean UPF 


\section{Results and discussion}

3.1 NDGA oxidation by laccase in aqueous-ethanol mixture

Due to the insolubility of NDGA in aqueous media, an appropriate aqueous/organic mixture to balance the need for dissolving the substrate with the need for maintaining catalytic activity of laccase is required to develop the enzymatic grafting of NDGA on wool. In our previous work an 80/20 (v/v \%) aqueous-ethanol mixture was optimized for enzymatic grafting of lauryl gallate on wool [25]. At this solvent to water ratio laccase retained $75-80$ $\%$ of its activity. To determine the ability of laccase to oxidize NDGA in this aqueousethanolic medium, UV/Vis spectrophotometry cannot be applied because no differences in the UV/Vis spectra of NDGA were observed during the enzymatic reaction. As phenolic compounds usually exhibit electrodic process and the use of electrochemistry to study enzymatic reactions on aqueous-organic media has been previously reported $[27,28]$, the catalytic oxidation of NDGA by laccase was studied using cyclic voltammetry. The cyclic voltammograms of NDGA alone and in the presence of laccase in an aqueous-ethanol mixture are shown in Fig. 1. The cyclic voltammogram of NDGA in 80/20 (v/v \%) $0.1 \mathrm{M}$ tartrate buffer - EtOH mixture $\mathrm{pH} 4$ shows a reversible electrodic process at $0.32 \mathrm{~V}$ (vs. $\mathrm{Ag} / \mathrm{AgCl})$. In the presence of laccase, a significant change in the shape of the corresponding signal was observed. A decrease in the anodic peak due to the catalytic but no electrodic oxidation of the phenolic compound, and a significant enlargement (catalytic current) of the cathodic current related to the reduction of the oxidised form of the phenolic compound generated by the enzymatic reaction was recorded. The oxidation of NDGA catalysed by laccase exhibited typical Michaelis-Menten saturation kinetics (data not shown) with an apparent Michaelis-Menten of $0.15 \mathrm{mM}$. 


\subsection{Enzymatic grafting of NDGA on wool fabrics}

To ensure that during the enzymatic modification of wool with laccase $(14 \mathrm{U} / \mathrm{mL})$ saturating substrate concentrations are reached, a $5 \mathrm{mM}$ concentration of NDGA ( $>10 \mathrm{~K}_{\mathrm{M}}$ ) was chosen to carry out all the experiments in this work. Nonspecific adsorption of NDGA on wool surface was minimised incorporating a cleaning step with 80/20\% (v/v) $\mathrm{H}_{2} \mathrm{O} /$ EtOH solution for $6 \mathrm{~h}$ followed by extensive washing with normal and distilled water at room temperature.

Similar to other phenolic compounds, the laccase oxidises NDGA into reactive quinones that can undergo either Schiff base or Michael's-type addition reaction with the amine groups of wool [29]. The enzymatic surface modification of wool fabrics was studied using DRIFT spectroscopy. The DRIFT spectra in Fig. 2 (A) show a significant difference between modified (line d) and unmodified wool fabrics (lines a, b and c) at $1576 \mathrm{~cm}^{-1}$, which difference can be assigned to the aromatic ring of NDGA [30]. Increasing absorption in the region of $1456 \mathrm{~cm}^{-1}$ and $1474 \mathrm{~cm}^{-1}$ (Fig. 2B) corresponding to the bending vibrations of $\mathrm{CH}_{2}$ and $\mathrm{CH}_{3}$ respectively is consistent with the presence of these groups in the NDGA moiety [31].

\subsection{Surface morphology of wool fabrics}

Clear differences were observed in the SEM micrographs of unmodified and NDGA modified wool fibres under the optimised conditions. As can be seen in Fig. 3 uneven deposition of NDGA onto the fibres surface was observed after the enzymatic process. 


\subsection{Tensile strength, shrink resistance and crease recovery angle}

Significant improvement in the shrink resistance and tensile strength (Fig. 4) as well as the crease recovery angle (Table 1) of the wool samples was observed after the enzymatic modification. The enzymatic grafting of NDGA on wool was able to reduce the fabric shrinkage after washing by $14 \%$ combined with an increase in the tensile strength up to about $24 \%$. The changes in these mechanical properties of wool could be related to the formation of inter/intramolecular bridges and cross-links in wool proteins in the presence of the multifunctional phenolic compound. NDGA could act as a cross-linking agent between the fibres due to the presence of two functional ortho-catechols in its structure through Schiff base or Michael's-type addition reactions with amines from wool. Furthermore, the deposition of NDGA on the surface causes resistance to movement across the fibre surface. Therefore, the differential friction effect is reduced with concomitant reduced felting shrinkage [32]. The improvement of wool shrink resistance and fibres strength by transglutaminase mediated croslinking on wool protein was also reported by other authors $[33,34]$. A $5 \%$ increase in the crease recovery angle (CRA) of the fabrics was further observed. This wrinkle-free behaviour could be attributed to the cross-linking of the fibres due to the enzymatic modification with NDGA [35].

\subsection{Antioxidant activity}

NDGA is widely used as a powerful antioxidant in food and cosmetic products [19]. Thus, antioxidant activity was expected on wool after NDGA grafting. The antioxidant activity of modified wool was determined by the $\mathrm{DPPH}^{*}$ method, which applies for both solid and liquid samples and is widely used to test the ability of compounds to act as free radical scavengers or hydrogen donors [36]. The enzymatically modified wool samples showed antioxidant 
activity expressed in $85 \%$ inhibition of DPPH compared to $15-30 \%$ of the control samples (data not shown).

\subsection{UV protection of modified wool}

During the last years there is a growing need for using textile products with effective protection against the UV-radiation responsible for skin damage such as skin cancer, sunburn, and photo-aging. In the case of wool, which has itself a good UV protection property, the most significant consequence of photo-oxidation is the phenomenon of photoyellowing [15]. Exposure of wool to UV-B radiation, in the range 280 to $320 \mathrm{~nm}$, results in a gradual yellow colouration of the fibres that is not recoverable by laundering. The photoyellowing takes place more rapidly in the wool cuticle than in the cortex and represents a serious problem for commercialisation of wool goods [37]. Recent studies revealed that NDGA could act as a protecting agent against keratosis caused by exposure to UV light [20]. Thus, the permanent incorporation of this UV absorber onto the fibres was expected to avoid the photoyellowing effects. All samples, both treated and untreated wool fabrics, showed high UV protection with UPF ratios of $50+$ (Table 2). However, it is interesting to note that the enzymatic modification in accordance with the transmittance spectra in Fig. 5 caused an increase on the UPF. The high UPF value obtained for the enzymatically modified fabrics confirmed the efficiency of NDGA against wool photoyellowing. 


\section{Conclusions}

Wool fabrics were modified with NDGA in an easy one-step enzymatic process carried out in $80 / 20(\mathrm{v} / \mathrm{v}, \%)$ aqueous-ethanol medium and catalysed by laccase. Electrochemical studies confirmed that laccase was able to catalyse the oxidation of this phenolic compound in aqueous-organic mixture. The covalent grafting of NDGA on wool was confirmed by the increase of methylene and aromatic groups signals in the DRIFT spectra of the modified fabric. The deposition of NDGA onto the wool fibres and the effect on the morphology of the cuticle scales was visualised by SEM analysis. The enzymatic grafting of the bi-functional phenolic compound on the fibres, combined to possible formation of inter/intramolecular bridges and cross-links in wool proteins provided a significant improvement of the physical and mechanical properties of the fabrics. Shrink resistance, crease recovery angle and tensile strength of the modified samples increased by $14 \%, 5 \%$ and $24 \%$ respectively compared to the untreated ones. NDGA grafting on wool provided also antioxidant activity expressed in about $85 \%$ inhibition of DPPH and was efficient protecting wool against the undesirable photoyellowing caused by UV radiation.

\section{Acknowledgments}

We gratefully acknowledge Agency for Administration of University and Research Grant (AGAUR) for a pre-doctoral contract for the financial support to this research. María Díaz González is grateful to Universitat Politècnica de Catalunya for a Postdoctoral research contract. 


\section{References}

[1] Negri AP, Cornell HJ, Rivett DE. A model for the surface of keratin fibers. Text Res J 1993; 63: 109-115.

[2] Holme I. New developments in the chemical finishing of textiles. J Text Inst 1993; 84: 520-531.

[3] Griffin M, Cortez JM, Bonner P. A method for enzymatic treatment of textiles such as wool. Biochem J 2002; 368: 377-396.

[4] Heine E, Hocker H. Enzyme treatments for wool and cotton. Rev Prog Coloration 1995; 25: 57-63.

[5] King RD, Brockway BE. Treatment of wool materials. University of Reading. EP0276547: 1988.

[6]. Silva CJSM, Cavaco-Paulo A. Treatment of animal hair fibers with modified proteases. University do Minho. WO03097927: 2003.

[7] Cortez J, Phillip LRB, Griffin M. Application of transglutaminases in the modification of wool textiles, Enzyme Microb Technol 2004; 34: 64-72.

[8] Du G, Cui L, Zhu Y, Chena J. Improvement of shrink-resistance and tensile strength of wool fabric treated with a novel microbial transglutaminase from Streptomyces hygroscopicus. Enzyme Microb Technol 2007; 40: 1753-1757.

[9] Gembeh SV, Jr. HMF, Taylor M, Brown EM, Marmer WN. Application of transglutaminase to derivatize proteins: 1 . Studies on soluble proteins and preliminary results on wool. J Sci Food Agric 2005; 85: 418-424

[10] McDevitt JP, Winkler J. Method for enzymatic treatment of wool. Novo Nordisk Biochem North America, Inc. US6051033: 2000.

[11] Gaffar Hossain KhM, Juan AR, Tzanov T. Simultaneous protease and transglutaminase treatment for shrink resistance of wool. Biocatal Biotrans 2008; 26: 405-411. 
[12] Anghileri A, Lantto R, Kruus K, Arosio C, Freddi G. Tyrosinase-catalyzed grafting of sericin peptides onto chitosan and production of protein-polysaccharide bioconjugates. J Biotechnol 2007; 127: 508-519

[13] Gambichler T, Avermaete A, Bader A, Altmeyer P, Hoffmann K. Ultraviolet protection by summer textiles. Ultraviolet transmission measurements verified by determ ination of the minimal erythema dose with solar-simulated radiation. Br J Dermatol. 2001; 144: 484-489..

[14] Schwartz L, Purcell HK, Wieselman JJ. Wrinkle removing product and process. RLR Chemical Company, Inc. US3674688: 1972.

[15] Millington KR, Photoyellowing of wool. Part 1: Factors affecting photoyellowing and experimental techniques. Color Technol 2006; 122: 169-186.

[16] Evans NA, Waters PJ. Photoprotection of wool by application of ultraviolet absorberpolymer mixtures to its surface. Text Res J 1981; 51: 432-434.

[17] Becheri A, Dürr M. Nostro PL, Baglioni P. Synthesis and characterization of zinc oxide nanoparticles: application to textiles as UV-absorbers. J Nanoparticle Res 2008; 10: 679-689. [18] Carr CM, Leaver IH. Photoprotective agents for wool. Synergism between UV absorbers and antioxidants. J Appl Polym Sci 1987; 33:2087-2095.

[19] Pillai S, Costello B, Bell S. Nordihydroguaiaretic acid (NDGA): A powerful antioxidant and anti-inflammatory ingredient for skin care applications. Fragr J 2006; 34:61-64. [20] Lluria-Prevatt LM, Alberts DS. Skin Cancer Prevention in Fundamentals of Cancer Prevention, 2nd edition, D. S. Alberts; L. M. Hess,Eds., Springer 2008; 239-275. [21] Koob TJ, Hernandez DJ. Mechanical and thermal properties of novel polymerized NDGA-gelatin hydrogels. Biomaterials 2002; 23:203-212.

[22] Haifeng L, Zigang G, Yue W, Siew Lok T, Sutthikhum V, Goh JCH. Modification of sericin-free silk fibers for ligament tissue engineering application. J Biomed Mat Res. Part B 2007; 82: 129-138. 
[23] Díaz Blanco C, Díaz González M, Daga Monmany JM, Tzanov T. Dyeing properties, synthesis, isolation and characterization of an in situ generated phenolic pigment, covalently bound to cotton. Enzyme Microb Technol 2009; 44: 380-385.

[24] Calafell M, Díaz C, Hadzhiyska H, Gibert JM, Dagà JM,. Tzanov T. Bio-catalyzed coloration of cellulose fibres. Biocatal Biotransform 2007; 25: 336-340.

[25] Gaffar Hossain KhM, Díaz González M, Rocasalbas Lozano G, Tzanov T. Multifunctional modification of wool using an enzymatic process in aqueous-organic media. J Biotechnol 2009; 141: 58-63.

[26] Fernández-Sánchez C, Tzanov T, Gübitz GM, Cavaco-Paulo A. Voltammetric monitoring of laccase-catalyzed mediated reactions. Bioelectrochemistry 2002; 58: 149- 156. [27] Bogdanovskaya VA, Kuznetsova LN, Tarasevich MR. Bioelectrocatalytic and enzymic activity of laccase in water-ethanol solutions. Russ J Electrochem 2002; 38: 1074-1081.

[28] Bogdanovskaya VA, Tarasevich MR, Kuznetsova LN, Reznik MF, Kasatkin, EV. Peculiarities of direct bioelectrocatalysis by laccase in aqueous-nonaqueous mixtures. Biosens Bioelectron 2002; 17: 945-951.

[29] Yamada K, Inoue T, Akiba Y, Kashiwada A, Matsuda K, Hirata M, Removal of palkylphenols from aqueous solutions by combined use of mushroom tyrosinase and chitosan beads. Biosci Biotechnol Biochem 2006; 70: 12467-2475.

[30] Jia YF, Thomas KM. Adsorption of cadmium ions on oxygen surface sites in activated carbon. American Chemical Society. 1999; 16; 1114-1122.

[31] Furer VL, Vandukova II, Tatarinova EA, Muzafarov AM, Kovalenko VI. FTIR spectroscopy and DFT studies of carbosilane dendrimers. Spectrochim Act, Part A 2008; 70: 692-699.

[32] Ryu J, Wakida T, Kawamura H, Goto T, and Takagishi T. Frictional Coefficient of Wool Treated with Low Temperature Plasma. Sen-i Gakkaishi 1987; 43: 257-262. 
[33] Cardamone JM. Enzyme-mediated Crosslinking of Wool. Part I: Transglutaminase. Text Res J 2007; 77: 214 -221.

[34] Cardamone JM, Phillips, JG. Enzyme-mediated Crosslinking of Wool. Part II: Keratin and Transglutaminase. Text Res J 2007; 77: 277-283.

[35] Hassan MS. Crease recovery properties of cotton fabrics modified by urea resins under the effect of gamma irradiation. Radiat Phys Chem 2009; 78: 333-337.

[36] Serpen A, Capuano E, Fogliano V, Gökmen V. A new procedure tomeasure the antioxidant activity of insoluble food components. J Agric Food Chem 2007; 55: 7676-7681. [37] Zhang H, Millington KR, Wang X. A morphology-related study on photodegradation of protein fibres. J Photochem Photobiol B Biol 2008; 92: 135-143. 


\section{Figure captions}

Figure 1. Cyclic voltammograms of $0.25 \mathrm{mM}$ of NDGA alone (-) and in the presence of laccase (—). Scan rate $5 \mathrm{mV} / \mathrm{s}$

Figure 2. Diffuse reflectance infrared Fourier transform (DRIFT) spectra in the range of 1420 $\mathrm{cm}^{-1}$ to $1490 \mathrm{~cm}^{-1}$ (B) and $1540 \mathrm{~cm}^{-1}$ to $1630 \mathrm{~cm}^{-1}$ (A) of: (a) untreated wool; (b) laccase

treated wool; (c) $5 \mathrm{mM}$ NDGA treated wool; (d) laccase and $5 \mathrm{mM}$ NDGA treated wool. Laccase, $14 \mathrm{U} / \mathrm{mL}$ in $80 / 20(\mathrm{v} / \mathrm{v}, \%)$ buffer/EtOH

Figure 3. SEM images (magnification x1500) of: (A) unmodified wool fabrics and (B) enzymatically modified wool fabrics in 80/20 (v/v, \%) buffer/EtOH. Laccase $14 \mathrm{U} \mathrm{ml}^{-1}$ and 5 mM NDGA.

Figure 4. Shrink-resistance (\%) and tensile strength increase (\%) of wool fabrics. C: unmodified wool; Lac: $14 \mathrm{U} / \mathrm{mL}$ laccase treated wool; NDGA: $5 \mathrm{mM}$ NDGA treated wool and Lac + NDGA: $14 \mathrm{U} / \mathrm{mL}$ laccase, $5 \mathrm{mM}$ NDGA modified wool in 80/20 (v/v, \%) buffer/EtOH

Figure 5. UV transmittance of wool fabrics. C: unmodified wool; Lac: $14 \mathrm{U} / \mathrm{mL}$ laccase treated wool; NDGA: 5 mM NDGA treated wool and Lac + NDGA: $14 \mathrm{U} / \mathrm{mL}$ laccase, $5 \mathrm{mM}$ NDGA modified wool in 80/20 (v/v, \%) buffer/EtOH.

Scheme 1. Chemical structure of nordihydroguaiaretic acid (NDGA) 
Scheme 1.

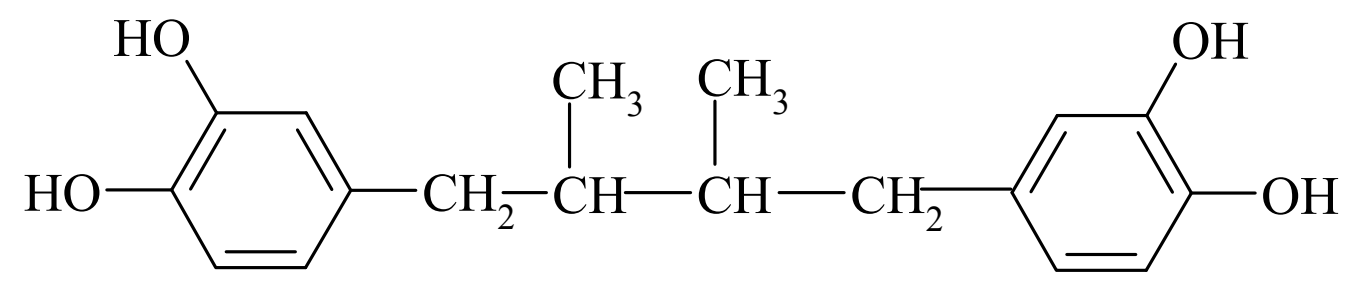


Figure 1

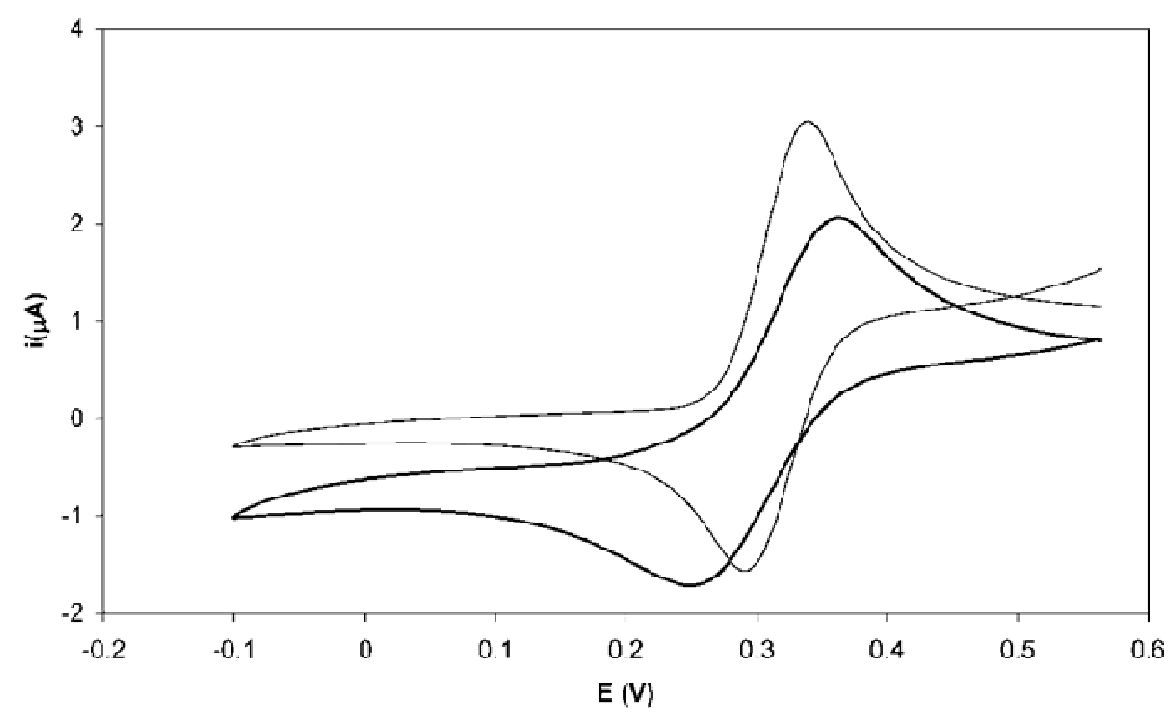


Figure 2

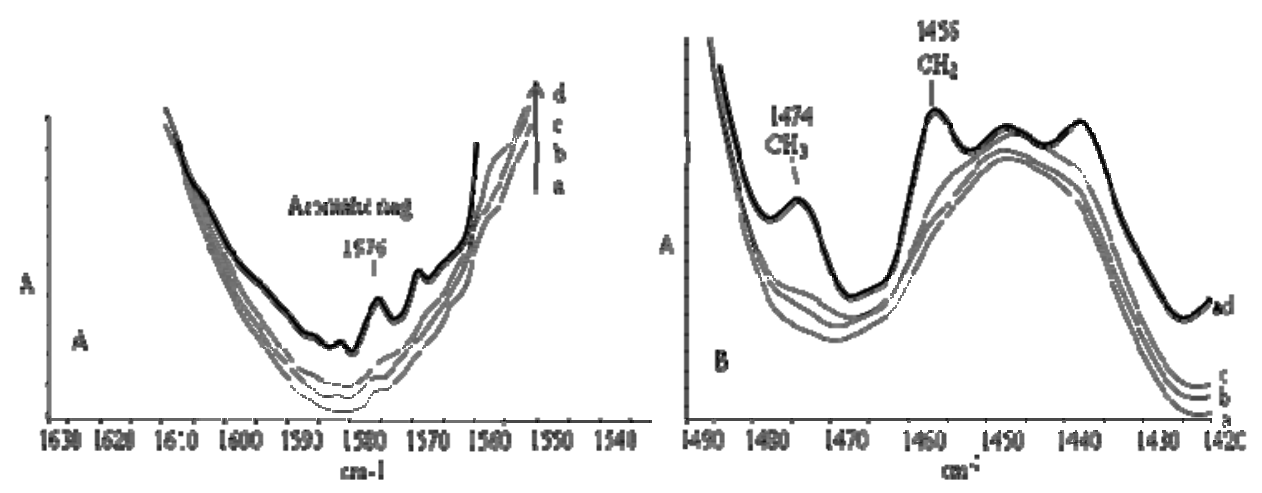


Figure 3
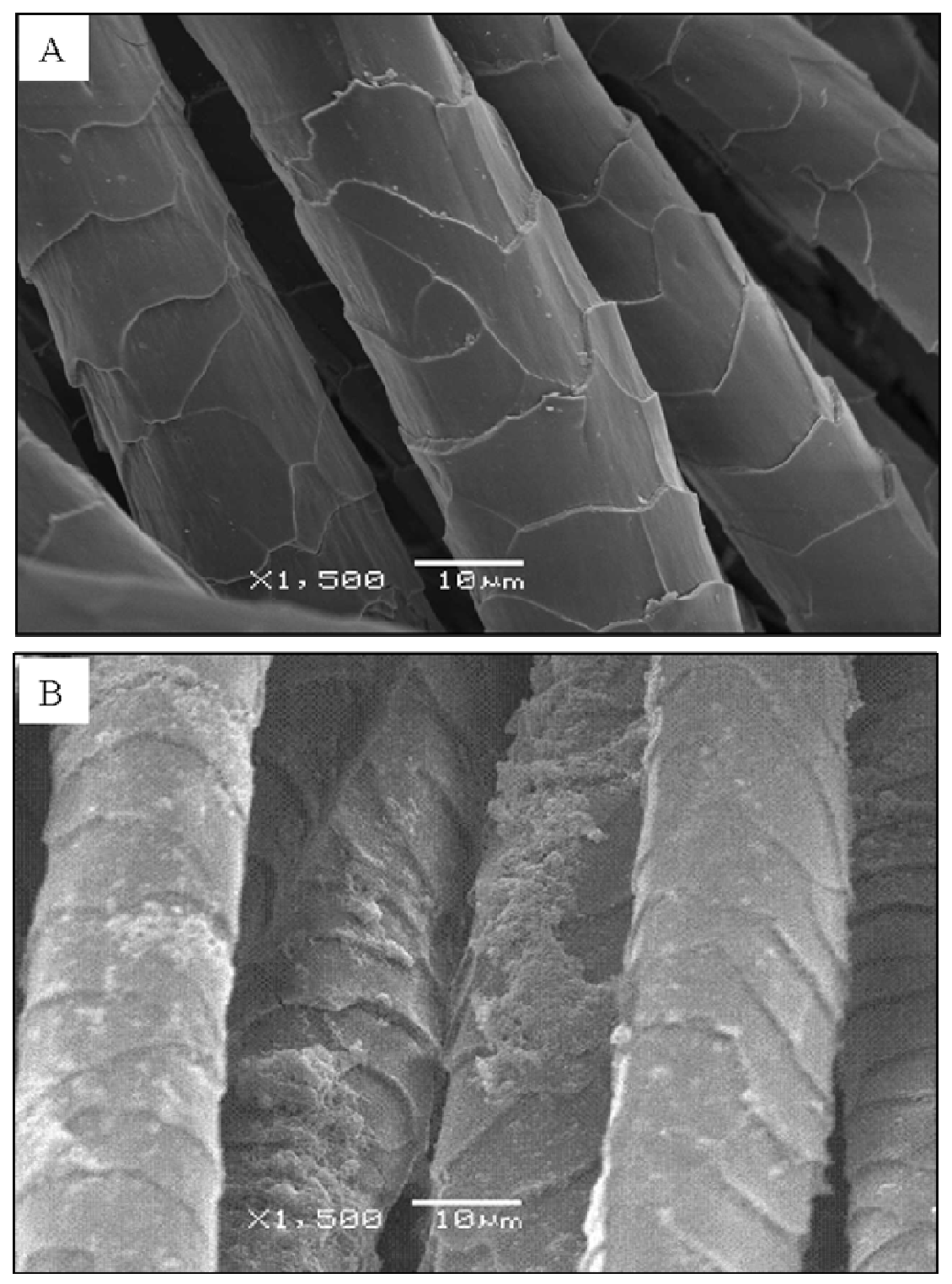
Figure 4

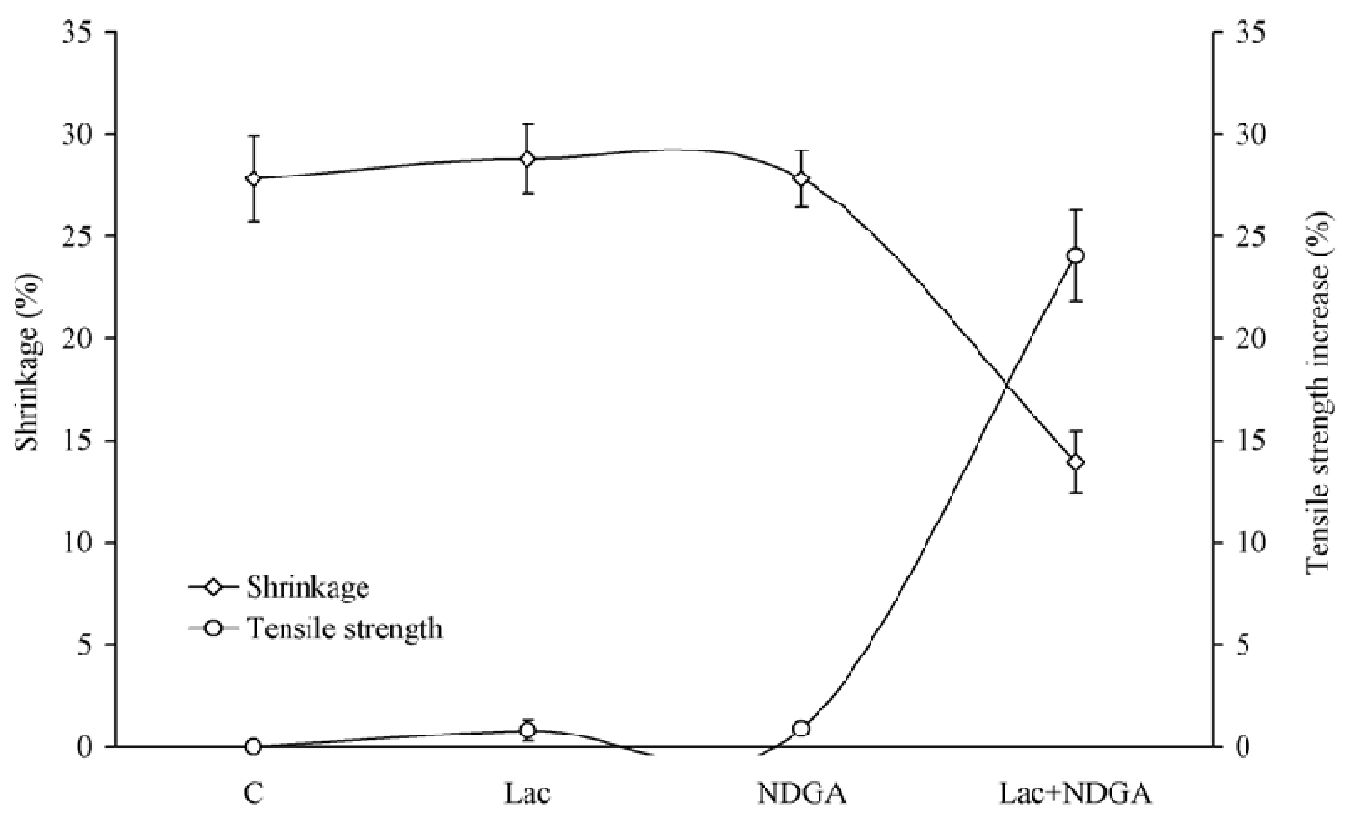


Figure 5

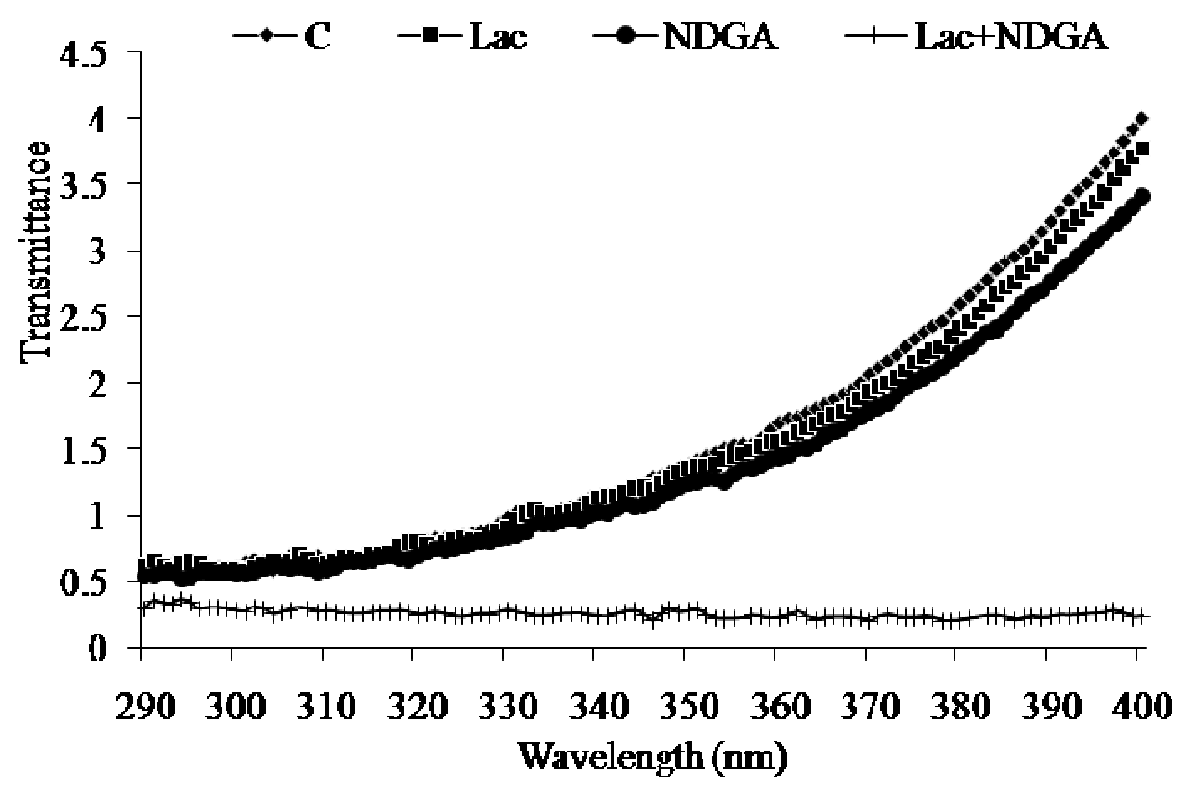




\section{Table 1}

Crease recovery angle (CRA) of wool fabrics

\begin{tabular}{cc} 
Wool sample & CRA \\
\hline C (unmodified) & $124.7 \pm 0.6$ \\
Lac $(14 \mathrm{U} / \mathrm{mL})$ & $124 \pm 2$ \\
NDGA $(5 \mathrm{mM})$ & $125 \pm 0.6$ \\
Lac + NDGA $(14 \mathrm{U} / \mathrm{mL}+5 \mathrm{mM})$ & $142 \pm 3$
\end{tabular}


Table 2

Parameters related to the UPF of wool fabric samples

\begin{tabular}{cccccc} 
& \multicolumn{3}{c}{ Transmittance (\%) } & \multirow{2}{*}{ UPF } & UPF ratio \\
\cline { 2 - 4 } & UVA & UVB & UVR & & \\
\cline { 2 - 4 } C(unmodified) & 1.86 & 0.64 & 1.58 & 122.58 & $50+$ \\
Lac $(14 \mathrm{U} / \mathrm{mL})$ & 1.76 & 0.64 & 1.50 & 128.42 & $50+$ \\
NDGA $(5 \mathrm{mM})$ & 1.61 & 0.59 & 1.38 & 136.82 & $50+$ \\
Lac + NDGA $(14 \mathrm{U} / \mathrm{mL}+5 \mathrm{mM})$ & 0.25 & 0.30 & 0.26 & 308.00 & $50+$
\end{tabular}

